\title{
Infection in Patients with Acute Stroke
}

\author{
S.P. Johnsen*, M.L. Svendsen and A. Ingeman
}

Department of Clinical Epidemiology, Aarhus University Hospital, Denmark

\begin{abstract}
Stroke is a major cause of mortality and morbidity worldwide and efforts to reduce the impact of the disease are strongly needed. Patients with acute stroke have an increased risk of in-hospital complications, in particular pneumonia and urinary tract infections. These infections are associated with an adverse patient outcome and increased health care costs. Here we review the existing knowledge on the risk and consequences of post-stroke pneumonia and UTI in adult patients and discuss the evidence of possible targets for intervention.
\end{abstract}

Keywords: Stroke, infections, incidence, clinical outcome, pneumonia, urinary tract infection.

\section{INTRODUCTION}

Stroke has a major global impact on mortality and morbidity. It is responsible for nearly six million deaths every year and thereby claims more lives than AIDS, tuberculosis and malaria put together [1-4]. Furthermore, it is a leading cause of permanent disability worldwide [5].

Patients with stroke are susceptible to a wide array of medical complications which have been linked with the clinical outcome. Infections, in particular pneumonia and urinary tract infections (UTI), are among the most frequent complications. Effective prevention and treatment of infections should therefore be an important component in any strategy aiming to reduce the impact of stroke.

Here we review the existing knowledge on this risk and consequences of post-stroke pneumonia and UTI in adult patients and discuss the evidence of possible targets for intervention.

\section{MECHANISMS LEADING TO POST-STROKE INFECTIONS}

A number of different mechanisms may increase the risk of infections in by patients with stroke (Fig. 1). These mechanisms may both be direct consequences from the brain injury caused by the stroke and indirect mechanisms caused by factors associated with but not caused by the stroke (eg., high age and comorbidity).

\section{Symptoms Caused by the Stroke}

As a direct consequence of the stroke, the patients often experience symptoms that may facilitate infections. These symptoms include immobility, dysphagia which increases the risk of aspiration, impaired cough reflexes and bladder dysfunction. The adverse impact of these symptoms on the risk of infections may be further strengthened by the difficulties or even inability of the patients to communicate and cooperate due to coma, aphasia, dementia and/or delirium.

*Address correspondence to this author at the Department of Clinical Epidemiology, Aarhus University Hospital, Olof Palmes Allé 43, DK-200 Aarhus N, Denmark; Tel: +45 871 68115;

E-mail: spj@dce.au.dk, dda@dce.au.dk

\section{Stroke Related Treatments}

Invasive procedures such as urinary catheters, intravenous lines and tubes used for mechanical ventilation constitute easily accessible routes for entering the body for pathogens. Permanent urinary catheters is associated with a particular high risk as it is associated with an absolute risk of urinary tract infections of $3-10 \%$ per day of catheterization leading to an almost $100 \%$ risk after 30 days in general medical populations $[6,7]$.

\section{Brain-Induced Immunodepression}

A growing body of evidence indicates that central nervous system mediated impairment of immune competence may lead to systemic infections in patients with central nervous system injuries including stroke, brain tumors, epilepsy, and traumatic brain injury [8-10]. The immunodepressive effect of central nervous system injuries is mediated through a number of humoral and neural pathways which include the hypothalamic pituitary adrenal axis, the vagus nerve and the sympathetic nervous system [8]. Reported defects in immune function in patients with stroke include reduced peripheral blood lymphocyte counts, impaired $\mathrm{T}$ - and natural killer cell activity, and reduced mitogen induced cytokine production and proliferation $[8,9]$.

\section{Patient Characteristics Related with Stroke}

Patients with stroke often have comorbidities including diabetes, chronic obstructive pulmonary disease and cancer which may increase the susceptibility for infections and complicate the prevention and treatment.

\section{LITERATURE SEARCH}

We conducted a systematic literature search in international databases in order to identify scientific publications that reports on in-hospital pneumonia and UTI in patients with stroke during hospitalization with a focus on risk, risk factors, and consequences.

The systematic search was initially conducted in PubMed, and followed by searches in The Cochrane Database and Google Scholar. The search strategy was based on a combination of free-text and MESH-terms search: 


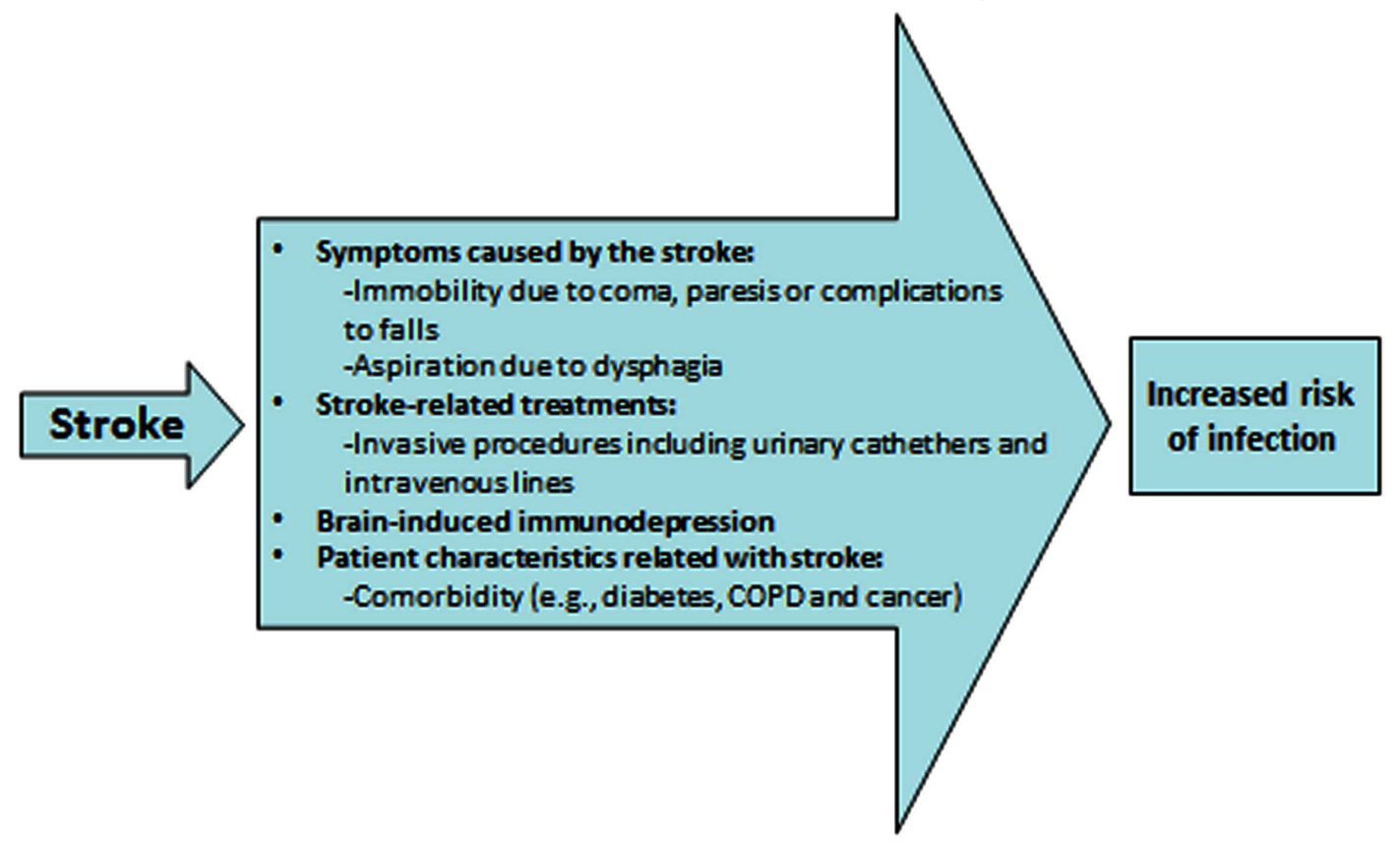

Fig. (1). Mechanisms leading to increased risk of post-stroke infections.

"Cerebrovascular Accident", "Cerebrovascular Disorders (MESH)", and "Stroke (MESH)", in combination with "pneumonia" and "urinary tract infection". The search was limited to include articles published in English and involving people age 18 or over. The literature and information search was completed in October 2011.

\section{RISK OF POST-STROKE PNEUMONIA AND UTI}

\section{Pneumonia}

Post-stroke pneumonia has been reported to occur during hospitalization $1.2 \%$ to $22 \%$ of patients admitted with acute stroke in the studies identified in our literature search [1141]. In a recent meta-analysis of 87 studies, Westendorp et al. reported a pooled estimate of $10 \%$ (95\% confidence interval [CI] 9-10\%), but also found significant heterogeneity between the studies with studies on intensive care unit patients reporting a substantially higher risk $(28 \%$, 95\%CI 18-38\%) [42].

Most medical complications and in particular pneumonia occur early, often as early as within the first 24 hours and rarely after 4 days [13]. Pneumonia is the most common cause of fever within the first 48 hours after an acute stroke $[24,43]$. Most stroke-related pneumonias are believed to result from aspiration [24].

A range of independent patient-related predictors of poststroke pneumonia have been identified. The findings are not entirely consistent but the list of predictors appear to include older age ( $>65$ years), preadmission dependency, speech impairment, severity of post-stroke disability, cognitive impairment, dysphagia, type of stroke (nonlacunar ischemic stroke) and comorbidities (chronic obstructive pulmonary disease, coronary artery disease) $[32,39]$.

\section{UTI}

The reported risk of in-hospital UTI varies substantially in the available studies with risks ranging from $3.7 \%$ to
$65.8 \%$ (Table 1). In their meta-analysis, Westendorp et al. found a pooled estimate of $10 \%(95 \% \mathrm{CI} 9-12 \%)$ [42]. As for pneumonia, the risk of UTI appears to be substantially higher in ICU patients (pooled estimate 20\%, 95\% CI 0-40\%) [42]. The median time from admission to post-stroke UTI has been reported to be 15-17 days [25, 28]. Factors found to predict UTI include stroke severity, depressed consciousness level, increased post-void residual urine volume, and diabetes mellitus $[13,27,28]$. The majority of hospitalacquired UTIs are associated with the use of indwelling catheters $[28,44]$ but whether catheterized or not, patients with stroke have more than double the odds for a UTI when compared with the general medical and surgical populations [30].

\section{CONSEQUENCES OF PNEUMONIA AND UTI IN PATIENTS WITH STROKE}

Infections have been associated with a poor outcome in patients with stroke because they may hinder optimum rehabilitation, increase the length of hospital stay and resource use and increase case-fatality [8]. In a recent population-based Danish study, pneumonia (adjusted ratio of length of stay 1.80, 95\%CI:1.54-2.11) and UTI (adjusted ratio of length of stay 2.29, 95\%CI:1.88-2.80) were associated with substantially longer length of hospital stay even after adjusting for a wide range of possible confounding factors [50]. The increased length of stay is of major importance since length of stay has been identified as the main cost-determining factor for patients with acute stroke.

Overall, post-stroke infections have in a recent metaanalysis also been shown to be associated with higher casefatality rates (crude OR 2.08, 95\% CI 1.63 - 2.67) [42]. The corresponding crude ORs of death associated with pneumonia and UTI were 5.58 (95\% CI: 4.76-6.55) and 1.12 (95\% CI: $0.76,1.66)$, respectively, in the metaanalysis [42]. Table 1 presents studies with focus on the association between post-stroke pneumonia, UTI and case-fatality. There 
Table 1. Selected Studies on the Association Between Pneumonia, UTI and Case-Fatality Among Patients with Stroke

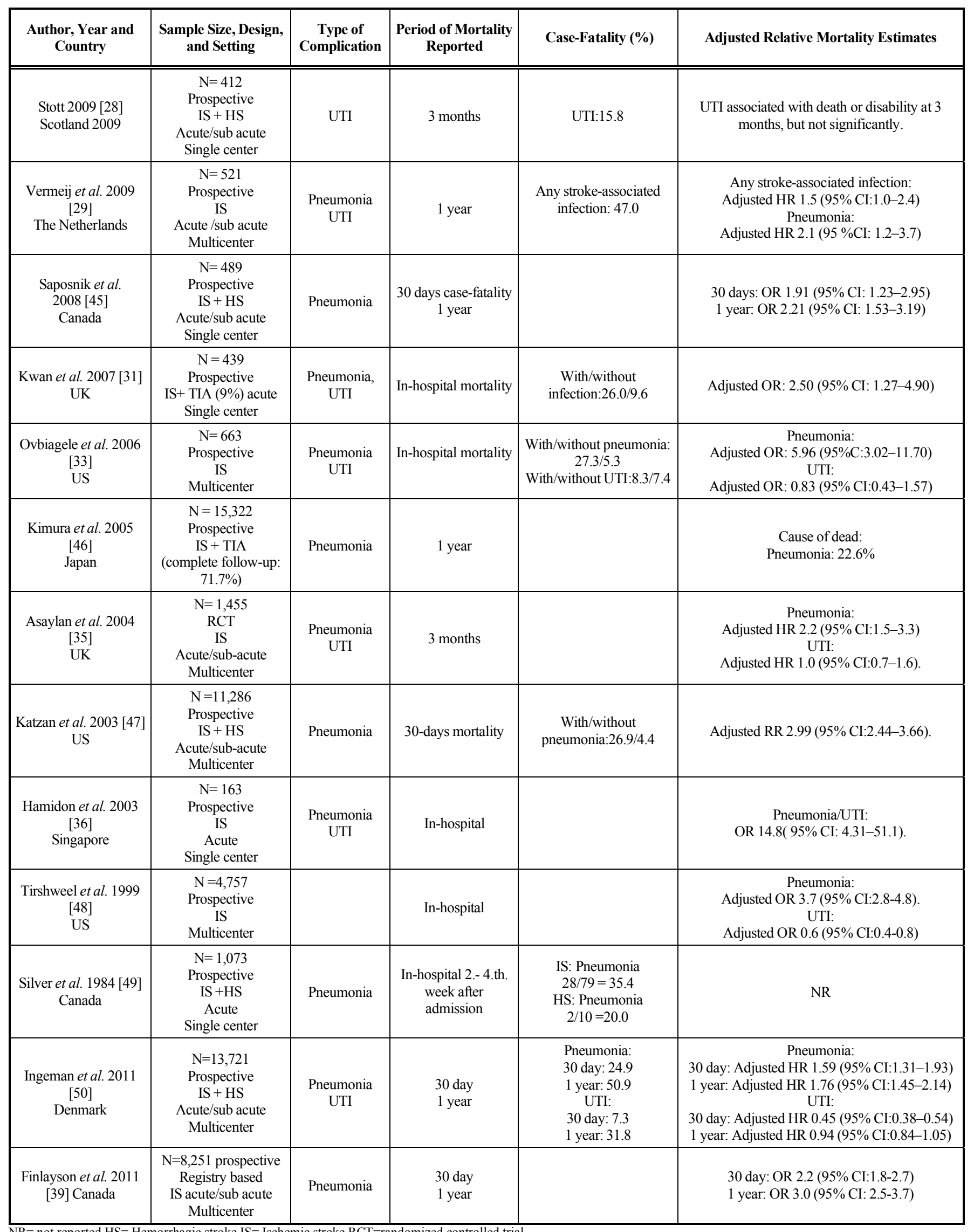

$\mathrm{NR}=$ not reported $\mathrm{HS}=$ Hemorrhagic stroke IS= Ischemic stroke $\mathrm{RCT}=$ randomized controlled trial. 
are major variations between the studies in design, size, length of follow-up and possibility of confounder control, however, altogether, the majority of the existing studies have shown that post-stroke pneumonia is a strong predictor of both short- and long-term morality, and suggested that proper management of pneumonia may improve short- and long-term prognosis for patients with acute stroke. A number of studies have found pneumonia to be a leading cause of death in the post-acute phase of stroke accounting for approximately one in three in-hospital deaths [34,47]. In contrast, data on UTI are more limited and inconsistent with some studies finding no significantly increased risk of mortality and others finding UTI to be associated with a decreased risk of in-hospital mortality.

The exact mechanisms underlying the association between post-stroke infection and poor clinical outcome are not well-defined. Several factors may be at play, including the factors also driving the increased risk of infections (Fig. 1). In addition, increasing evidence demonstrate that immunity and inflammation are key elements of the pathobiology of stroke and may also play a central role in relation to the clinical impact of post-stroke infections [51]. Thus, experimental data suggest that animals subjected to a systemic inflammatory insult simulating an infection at the time of stroke are predisposed to develop an autoimmune response to the brain, and that this response is associated with worse outcome [52].

\section{POSSIBLE TARGETS FOR INTERVENTION}

Given the high risk and the adverse effects of post-stroke infections, it is obviously of major importance to identify effective methods for reducing the risk of infections in patients with stroke. Promising targets for intervention includes:

\section{Preventive Use of Antibiotics}

A number of trials have in recent years evaluated preventive use of antibiotics in patients with acute stroke. Westendorp et al. identified 5 randomized clinical trials in their systematic review from 2012 [53]. The trials included a total of 506 patients of whom $94 \%$ had ischemic stroke. Study interventions were fluoroquinolones (2 studies), tetracycline ( 1 study), penicillin (1 study) or a combination of beta-lactam antibiotic with beta-lactamase inhibitor (1 study). Therapy was in all studies started within 24 hours of stroke onset and lasted between 3 and 5 days. Overall, the risk of infection was significantly lower among the patients receiving antibiotics group than among patients in the placebo/control group ( $22 \%$ versus $36 \%$, corresponding to a pooled RR for infection of $0.58,95 \%$ CI: $0.43-0.79)$. Thirtythree of 248 patients $(13 \%)$ in the antibiotic group died compared with 38 of $258(15 \%)$ in the placebo/control group (pooled RR for mortality $0.85,95 \%$ CI: $0.47-1.51$ ). No major harm or toxicity was reported. Although promising, the small scale and the conflicting results of the individual trials warrant further evaluation of preventive antibiotics in large scale clinical trials before any firm recommendations on routine use of preventive antibiotics can be made $[53,54]$.

\section{Reducing Use of Permanent Urinary Catheters}

Because use of urinary catheters is so strongly associated with the risk of UTI both in the general medical population and in patients with stroke, reducing the use or decreasing their infectious risk will lower the risk of UTI [55]. Antiseptic-coated catheters, including silver alloy and antibiotic- impregnated catheters, appear to reduce the risk of asymptomatic bacteruria, however, so far only small scale studies have been published and studies on symptomatic UTI are lacking [55]. Educational interventions and other methods to reduce inappropriate use of permanent catheters have also been examined and found promising although randomized data from stroke populations are lacking [55]. Alternatively, intermittent catheterization methods or, in men, condom catheters may be used to avoid permanent indwelling catheters.

\section{Organized In-Patient Care}

In a Cochrane review, which included three randomized clinical trials and 12 nonrandomized studies, patient management with stroke care pathways was found to be associated with a lower risk of developing certain complications, including UTI [56]. No statistical significant differences in risk were found for other complications such as pneumonia, deep venous thrombosis, and pressure sores; although the point estimates indicated that patient management with stroke care pathways might have a protective effect. Numerous trials have also documented the efficacy of stroke unit care [57]. Many questions remain about the specific processes responsible for this effect; however, a key difference between stroke unit care and general wards seems to be earlier initiation of rehabilitation and mobilization and careful monitoring of clinical parameters [57]. Early mobilization appears to play a pivotal role in reducing the risk of complications including infections. In a population-based Danish follow-up study, mobilization within the first post-admission day was associated with a substantially lower risk of pneumonia (adjusted OR 0.43, 95\% CI:0.34-0.54) and UTI (adjusted OR 0.56 , 95\%CI:0.47-0.66) [38]. The advantage of early mobilization was also confirmed in a recent randomized clinical trial, where early mobilization in the form of passive turning and mobilization during the acute phase of an ischemic stroke decreased the incidence of pneumonia [58]. The optimal timing of mobilization has so far been unclear, but mobilization within the first few days seems to be well tolerated and not harmful [59].

Early assessments of swallowing is another tool considered essential for preventing aspiration although there is only limited data on the accuracy of the available screening methods and the effectiveness of subsequent interventions in high risk patients, including patients with reduced consciousness and swallowing disturbances.

Recommendations from the American Heart Association [60] and the European Stroke Initiative [61] on prevention of infections in patients with stroke are summarized in Table 2.

\section{CONCLUSIONS}

Infections, in particular pneumonia and UTI, are common complications in patients admitted with acute stroke and associated with an adverse outcome. The infections are often preventable or, when prevention is not possible, amenable to early recognition and treatment in order to avoid serious consequences. Use of care pathways in acute stroke care and an early multidisciplinary effort to ensure optimal care, in 
Table 2. Recommendations from the American Heart Association [60] and the European Stroke Initiative [61] on Prevention of Infections in Patients with Stroke

\begin{tabular}{|c|c|c|}
\hline Area & American Heart Association & European Stroke Initiative \\
\hline Preventive use of antibiotics & $\begin{array}{l}\text { Prophylactic administration of antibiotics is not } \\
\text { recommended } \\
\text { (Class III, Level of Evidence B). }\end{array}$ & $\begin{array}{l}\text { Prophylactic administration of antibiotics is not recommended, and } \\
\text { levofloxacin can be detrimental in acute stroke patients (Class II, } \\
\text { Level B) }\end{array}$ \\
\hline $\begin{array}{l}\text { Reducing use of permanent } \\
\text { urinary catheters }\end{array}$ & $\begin{array}{l}\text { If possible, the placement of indwelling bladder catheters } \\
\text { should be avoided because of the associated risk of urinary } \\
\text { tract infections (Class III, Level of Evidence C). } \\
\text { Some patients may need prolonged catheter drainage of the } \\
\text { bladder, and measures to lower risk of infection should be } \\
\text { taken. }\end{array}$ & $\begin{array}{l}\text { In stroke patients with urinary incontinence, specialist assessment } \\
\text { and management is recommended (Class III, Level C) }\end{array}$ \\
\hline Early mobilization & $\begin{array}{l}\text { Early mobilization of less severely affected patients and } \\
\text { measures to prevent subacute complications of stroke are } \\
\text { recommended (Class I, Level of Evidence C). }\end{array}$ & $\begin{array}{l}\text { Early mobilization is recommended to prevent complications such as } \\
\text { aspiration pneumonia, DVT and pressure ulcers (Class IV, Good } \\
\text { Clinical Practice) }\end{array}$ \\
\hline Swallowing assessment & $\begin{array}{l}\text { Assessment of swallowing before starting eating or drinking } \\
\text { is recommended (Class I, Level of Evidence B). }\end{array}$ & $\begin{array}{l}\text { Swallowing assessment is recommended but there are insufficient } \\
\text { data to recommend a specific approach for treatment (Class III, } \\
\text { Good Clinical Practice) }\end{array}$ \\
\hline
\end{tabular}

particular early mobilization and minimized use of permanent urinary catheters, appear to be effective in reducing the risk of infections.

\section{CONFLICT OF INTEREST}

The authors confirm that this article content has no conflicts of interest.

\section{ACKNOWLEDGEMENT}

Declared none.

\section{REFERENCES}

[1] Truelsen T, Heuschmann PU, Bonita R, et al. Standard method for developing stroke registers in low-income and middle income countries: experiences from a feasibility study of a stepwise approach to stroke surveillance (STEPS Stroke). Lancet Neurol 2007; 6: 134-9.

[2] AIDS Epidemic Update. Geneva: UNAIDS/WHO. 2009.

[3] World Health Organization, Malaria Fact Sheet No. 94, Updated January 2009. Available at: http://www.who. int/mediacentre/fact sheets/fs094/en/index.html

[4] WHO/Stop TB Partnership. 2009 Update. Tuberculosis Facts. Available at: www.who.int/tb

[5] Sousa RM, Ferri CP, Acosta D, et al. Contribution of chronic diseases to disability in elderly people in countries with low and middle incomes: a 10/66 Dementia Research Group populationbased survey. Lancet 2009; 374: 1821-30.

[6] Maki DG, Tambyah PA. Engineering out the risk for infection with urinary catheters. Emerging Infect Dis 2001; 7: 342-7.

[7] Gould CV, Umscheid CA, Agarwal RK, Kuntz G, Pegues DA. Healthcare Infection Control Practices Advisory Committee (HICPAC). Guideline for the prevention of catheter-associated urinary tract infections. Infect Control Hosp Epidemiol 2010; 31: $319-26$

[8] Emsley HCA, Hopkins SJ. Acute ischaemic stroke and infection: recent and emerging concepts. Lancet Neurol 2008; 7: 341-53.
[9] Chamorro A, Urra X, Planas AM. Infection after acute ischemic stroke. A manifestation of brain-induced immunodepression. Stroke 2007; 38: 1097-103.

[10] Manousakis G, Jensen MB, Chacon MR, Sattin JA, Levine RL. The interface between stroke and infectious disease: Infectious diseases leading to stroke and infections complicating stroke. Curr Neurol Neurosci Rep 2009; 9: 28-34

[11] Sorbello D, Dewey HM, Churilov L, et al. Very early mobilisation and complications in the first 3 months after stroke: further results from phase II of A Very Early Rehabilitation Trial (AVERT). Cerebrovasc Dis 2009; $28: 378-83$.

[12] Hong KS, Kang DW, Koo JS, et al. Impact of neurological and medical complications on 3-month outcomes in acute ischaemic stroke. Eur J Neurol 2008; 15: 1324-31.

[13] Indredavik B, Rohweder G, Naalsund E, Lydersen S. Medical complications in a comprehensive stroke unit and an early supported discharge service. Stroke 2008; 39: 414-20.

[14] McLean R. Incidence of complications in stroke patients in an acute rehabilitation unit in Singapore. Cerebrovasc Dis 2007; 24: 129-32.

[15] Rocco A, Pasquini M, Cecconi E, et al. Monitoring after the acute stage of stroke: a prospective study. Stroke 2007; 38: 1225-8.

[16] Kuptniratsaikul V, Kovindha A, Suethanapornkul S, Manimmanakorn N, Archongka Y. Complications During the Rehabilitation Period in Thai Patients with Stroke: A Multicenter Prospective Study. Am J Phys Med Rehabil 2009; 88: 92-9.

[17] Bae HJ, Yoon DS, Lee J, et al. In-hospital medical complications and long-term mortality after ischemic stroke. Stroke 2005; 36: 2441-5.

[18] Hung JW, Tsay TH, Chang HW, Leong CP, Lau YC. Incidence and risk factors of medical complications during inpatient stroke rehabilitation. Chang Gung Med J 2005; 28: 31-8.

[19] McLean DE. Medical complications experienced by a cohort of stroke survivors during inpatient, tertiary-level stroke rehabilitation. Arch Phys Med Rehabil 2004; 85: 466-9.

[20] Doshi VS, Say JH, Young SH, Doraisamy P. Complications in stroke patients: a study carried out at the Rehabilitation Medicine Service, Changi General Hospital. Singapore Med J 2003; 44: 64352.

[21] Weimar C, Roth MP, Zillessen G, et al. Complications following acute ischemic stroke. Eur Neurol 2002; 48: 133-40. 
[22] Roth EJ, Lovell L, Harvey RL, Heinemann AW, Semik P, Diaz S. Incidence of and risk factors for medical complications during stroke rehabilitation. Stroke 2001; 32: 523-9.

[23] Langhorne P, Stott DJ, Robertson L, et al. Medical complications after stroke: a multicenter study. Stroke 2000; 31: 1223-9.

[24] Johnston KC, Li JY, Lyden PD, et al. Medical and neurological complications of ischemic stroke: experience from the RANTTAS trial. RANTTAS Investigators. Stroke 1998; 29: 447-53.

[25] Davenport RJ, Dennis MS, Wellwood I, Warlow CP. Complications after acute stroke. Stroke 1996; 27: 415-20.

[26] Kalra L, Yu G, Wilson K, Roots P. Medical complications during stroke rehabilitation. Stroke 1995; 26: 990-4.

[27] Dromerick A, Reding M. Medical and neurological complications during inpatient stroke rehabilitation. Stroke 1994; 25: 358-61.

[28] Stott DJ, Falconer A, Miller H, Tilston JC, Langhorne P. Urinary tract infection after stroke. QJM 2009; 102: 243-9.

[29] Vermeij FH, Scholte op Reimer WJ, de Man P, et al. Strokeassociated infection is an independent risk factor for poor outcome after acute ischemic stroke: data from the Netherlands Stroke Survey. Cerebrovasc Dis 2009; 27: 465-71.

[30] Ersoz M, Ulusoy H, Oktar MA, Akyuz M. Urinary tract infection and bacteriurua in stroke patients: frequencies, pathogen microorganisms, and risk factors. Am J Phys Med Rehabil 2007; 86: 734-41.

[31] Kwan J, Hand P. Infection after acute stroke is associated with poor short-term outcome. Acta Neurol Scand 2007; 115: 331-8.

[32] Sellars C, Bowie L, Bagg J, et al. Risk factors for chest infection in acute stroke: a prospective cohort study. Stroke 2007; 38: 2284-91.

[33] Ovbiagele B, Hills NK, Saver JL, Johnston SC. Frequency and determinants of pneumonia and urinary tract infection during stroke hospitalization. J Stroke Cerebrovasc Dis 2006; 15: 209-13.

[34] Heuschmann PU, Kolominsky-Rabas PL, Misselwitz B, et al. Predictors of in-hospital mortality and attributable risks of death after ischemic stroke: the German Stroke Registers Study Group. Arch Intern Med 2004; 164: 1761-8.

[35] Aslanyan S, Weir CJ, Diener HC, Kaste M, Lees KR. Pneumonia and urinary tract infection after acute ischaemic stroke: a tertiary analysis of the GAIN International trial. Eur J Neurol 2004; 11: 4953.

[36] Hamidon BB, Raymond AA, Norlinah MI, Jefferelli SB. The predictors of early infection after an acute ischaemic stroke. Singapore Med J 2003; 44: 344-6.

[37] Kammersgaard LP, Jorgensen HS, Reith J, et al. Early infection and prognosis after acute stroke: the Copenhagen Stroke Study. J Stroke Cerebrovasc Dis 2001; 10: 217-21.

[38] Ingeman A, Andersen G, Hundborg HH, Svendsen ML, Johnsen SP. Processes of care and medical complications in patients with stroke. Stroke 2011; 42: 167-72.

[39] Finlayson O, Kapral M, Hall R, Asllani E, Selchen D, Saposnik G. Risk factors, inpatient care, and outcomes of pneumonia after ischemic stroke. Neurology 2011; 77: 1338-45.

[40] Kitisomprayoonkul W, Sungkapo P, Taveemanoon S, Chaiwanichsiri D. Medical complications during inpatient stroke rehabilitation in Thailand: a prospective study. J Med Assoc Thai 2010; 93: 594-600.

[41] Tong X, Kuklina EV, Gillespie C, George MG. Medical complications among hospitalizations for ischemic stroke in the United States from 1998 to 2007. Stroke 2010; 41: 980-6.
[42] Westendorp WF, Nederkoorn PJ, Vermeij JD, Dijkgraaf MG, de Beek D. Post-stroke infection: A systematic review and metaanalysis. BMC Neurol 2011; 11: 110.

[43] Grau AJ, Buggle F, Schnitzler P, Spiel M, Lichy C, Hacke W. Fever and infection early after ischemic stroke. J Neurol Sci 1999; 171: 115-20

[44] Thomas LH, Cross S, Barrett J, et al. Treatment of urinary incontinence after stroke in adults. Cochrane Database Syst Rev 2008; (1): CD004462.

[45] Saposnik G, Hill MD, O'Donnell M, Fang J, Hachinski V, Kapral MK. Variables associated with 7-day, 30-day, and 1-year fatality after ischemic stroke. Stroke 2008; 39: 2318-24.

[46] Kimura K, Minematsu K, Kazui S, Yamaguchi T. Mortality and cause of death after hospital discharge in 10,981 patients with ischemic stroke and transient ischemic attack. Cerebrovasc Dis 2005; 19: 171-8.

[47] Katzan IL, Cebul RD, Husak SH, Dawson NV, Baker DW. The effect of pneumonia on mortality among patients hospitalized for acute stroke. Neurology 2003; 60: 620-5.

[48] Tirschwell DL, Kukull WA, Longstreth WT, Jr. Medical complications of ischemic stroke and length of hospital stay: experience in Seattle, Washington. J Stroke Cerebrovasc Dis 1999; 8: 336-43.

[49] Silver FL, Norris JW, Lewis AJ, Hachinski VC. Early mortality following stroke: a prospective review. Stroke 1984; 15: 492-6.

[50] Ingeman A, Andersen G, Hundborg HH, Svendsen ML, Johnsen SP. In-hospital medical complications, length of stay, and mortality among stroke unit patients. Stroke 2011; 42: 3214-8.

[51] Iadecola C, Anrather J. The immunology of stroke: from mechanisms to translation. Nat Med 2011; 17: 796-808.

[52] Becker KJ, Kindrick DL, Lester MP, Shea C, Ye ZC. Sensitization to brain antigens after stroke is augmented by lipopolysaccharide. J Cereb Blood Flow Metab. 2005; 25(12): 1634-44.

[53] Westendorp WF, Vermeij JD, Vermeij F, et al. Antibiotic therapy for prventing infections in patients with acute stroke. Cochrane Database Syst Rev 2012; (1): CD008530.

[54] Nederkoorn PJ, Westendorp WF, Hooijenga IJ, et al. Preventive antibiotics in stroke study: rationale and protocol for a randomised trial. Int J Stroke 2011; 6: 159-63.

[55] Poisson SN, Johnston SC, Josephson SA. Urinary tract infections complicating stroke: Mechanisms, consequences, and possible solutions. Stroke 2010; 41: e180-4.

[56] Kwan J, Sandercock P. In-hospital care pathways for stroke. Cochrane Database Syst Rev 2004; (4): CD002924.

[57] Langhorne P, Dennis MS. Stroke Units: An evidence based approach. London: BMJ Books 1998.

[58] Cuesy PG, Sotomayor PL, Pina JO. Reduction in the incidence of poststroke nosocomial pneumonia by using the "turn-mob" program. J Stroke Cerebrovasc Dis 2010; 19: 23-8.

[59] Bernhardt J, Thuy MN, Collier JM, Legg LA. Very early versus delayed mobilisation after stroke. Cochrane Database Syst Rev 2009; (1): CD006187.

[60] Adams Jr HP, del Zoppo G, Alberts MJ, et al. Guidelines for the early management of adults with ischemic stroke. Stroke 2007; 38 1655-711.

[61] European Stroke Organisation (ESO) Executive Committee; ESO Writing Committee. Guidelines for management of ischaemic stroke and transient ischaemic attack. Cerebrovasc Dis 2008; 25: 457-507.

This is an open access article licensed under the terms of the Creative Commons Attribution Non-Commercial License (http: //creativecommons.org/licenses/by$\mathrm{nc} / 3.0 /$ ) which permits unrestricted, non-commercial use, distribution and reproduction in any medium, provided the work is properly cited. 